\title{
Experimental analysis of orthogonal micro-machined surface features and chip morphology of AISI1215 steel by using EBSD method
}

\author{
S. Yadav $^{1 *}$, R. Waikar ${ }^{2}$, R. Pawade ${ }^{3}$, S. Joshi ${ }^{4}$ \\ ${ }^{1}$ UG Student, ${ }^{2}$ PG Student, ${ }^{3}$ Associate Professor, Dr. Babasaheb Ambedkar Technological University, Lonere, India \\ ${ }^{4}$ Professor Indian Institute of Technology Powai, Mumbai, India \\ \{spyadav@dbatu.ac.in\}
}

\begin{abstract}
In this work analysis of fundamental aspects of orthogonal microcutting was carried out in terms of variables like shear angle, chip thickness, chip morphology as a function of cutting speed, depth of cut, tool rake angle and heat treatment provided to the work specimen. Analysis of results shows that the material flow pattern at low cutting speed is highly inhomogeneous, which affects segmented chip formation. As the uncut chip thickness approaches the minimum chip thickness, chips are formed by shearing of the workpiece, with some elastic deformation still occurring. At the highest depth of cut of $100 \mu \mathrm{m}$, shear angle is fairly dependent on the rake angle. AISI 1215 steel heat treated at $1200^{\circ} \mathrm{C}$, shows the lowest shear angle at all the depths of cut at $5^{\circ}$ or $10^{\circ}$ of rake angle. Analyses of chip segment per unit length show that, the number of segments reduces as the rake angle increases for all the four work materials that were heat treated at the various temperatures.
\end{abstract}

Keywords: Micromachining, Chip formation, Cutting force, AISI 1215 steel

\section{Introduction}

The principles of micro-cutting are similar to those of conventional cutting operations. The surface of the workpiece is mechanically removed using micro-tools. Unlike conventional macro-machining processes, microcutting displays different characteristics due to its significant size reduction. Trend of miniaturization of products and consequently its components nowadays can be evident in almost every production field. To accomplish requirements imposed by miniaturization, micromachining has proved to be a satisfied manufacturing technique. Masuzawa and Tonshoff [1] have defined the range of uncut chip thickness for microcutting as 0.1 to $200 \mu \mathrm{m}$. Larger uncut chip thickness is normally used in "rough" machining operations to increase the material removal rate. Smaller uncut chip thickness is normally used in finishing operations. A number of features can be used to characterize and define the scope of micro cutting such as uncut chip thickness, dimensions and accuracy of micro parts or features, cutting tool geometry, underlying cutting mechanics, application area.

According to Dornfeld et al., [2] crystalline grain size of most work-piece materials is of the same order as the depth of cut in micro-cutting, so that chip formation normally takes place by the breaking up of the individual grains of a polycrystalline material. Most polycrystalline materials are thus treated as a collection of grains with random orientation and isotropic properties [2]. The crystalline graphic-orientation affects the chip formation, the surface generation, and the variation in the cutting forces [3]. There is a distinct difference between microcutting and conventional cutting, where the material can be treated as isotropic and homogeneous. To et al. [4] demonstrated the effects of crystallographic orientation and depth of cut on the surface roughness in diamond turning of single-crystal aluminium rods. Moriwaki et al. [5] conducted in situ machining experiments inside a SEM on single-crystal copper in various cutting direction at depths of cut ranging from 0.1 to $5 \mathrm{~mm}$ and a cutting speed of $120 \mathrm{~mm} / \mathrm{min}$. They found that the crystallographic orientation influence the chip formation process in terms of magnitude of the shear angle and the cutting forces. The shear angle was found to reach values as high as $60^{\circ}$.

B. Iyer, S. Nalbalwar and R. Pawade (Eds.)

ICCASP/ICMMD-2016. Advances in Intelligent Systems Research.

Vol. 137, Pp. 304-310.

(C) 2017. The authors - Published by Atlantis Press

This is an open access article under the CC BY-NC license (http://creativecommons.org/licens)es/by-nc/4.0/).

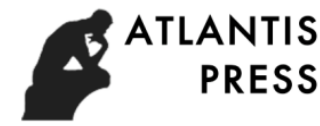


Liu et al. [6] demonstrated that there is elastic-deformation of the workpiece during micro-cutting process.Moriwaki et al. [5] used the Finite Element (FE) method to analyse orthogonal micromachining with the effect of tool edge radius. FE model showed good agreement with experimental cutting of copper with a sharpdiamond tool. Vogler et al. [7] determined the minimum chip thickness of steel by using an FE simulation tool. They reported the critical chip thickness as 0.2 and 0.3 times the edge radius for pearlite and ferrite, respectively. Lo [8] developed the elastic-plastic finite element method to investigate the effect of the tool rake angle on the chip and machined workpiece during precision cutting process.

With an increase in tool rake angle from $5^{0}$ to $15^{\circ}$, the changes in the above-mentioned physical phenomena are more pronounced. In contrast, the increase of tool rake angle from $15^{\circ}$ to $20^{\circ}$ hardly brought about any changes to these physical phenomena. Thus, reducing the cutting force in micromachining operations significantly improves material removal productivity, decrease tool deflection and tool wear, delay tool failure, and narrow workpiece tolerance limits. Pawade and Joshi [9] performed scanning electron microscopy of chips which revealed that the cracks extend from tool nose side up to $1 / 2$ to $3 / 4^{\text {th }}$ width of the chips. The rest of chip thickness was removed by ductile-type deformation. It was also observed that at $125 \mathrm{~m} / \mathrm{min}$, the chip thickness ratio $\left(\mathrm{t} / \mathrm{t}_{\mathrm{c}}\right)$ was higher which was attributed to thinner chips that was produced during machining of Inconel 718. The works done by Ernst [10] and Merchant [11] previously were based on the concern of forces in the shear plane and on the tool-chip interface. The development of theory of plasticity resulted in various slip-line models of orthogonal cutting.

Lee et al [12] studied the material anisotropy which plays an important role in the formation of shear angle in metal cutting. Crystallographic textures contribute to an important source of material anisotropy. The most likely shear angle is the one at which the Taylor factor is minimum. A good agreement was found between the predicted shear angle in machining a polycrystalline OFHC copper and the experimental data reported. Pawade et al. [13] observed that as the cutting speed increases from $60 \mathrm{~m} / \mathrm{min}$ to $120 \mathrm{~m} / \mathrm{min}$, the chip thickness ratio decreases by small value. However, further increase in the cutting speed to $180 \mathrm{~m} / \mathrm{min}$ causes increase in the chip thickness ratio. It is observed from their work that at lower and medium cutting speed of $60 \mathrm{~m} / \mathrm{min}$ and 120 $\mathrm{m} / \mathrm{min}$ respectively, the chip thickness ratio follows the decreasing trend, which agrees to the fundamentals of metal cutting [13]. Simoneau et al. [14] concluded that microstructure has a significant effect on micro- scale cutting. They analysed the effect of grain size and orientation during micro-cutting of AISI 1045 steel. Thus it is clear that the work on analysing the chip formation in micromachining is not adequate. Thus to understand the effect of machining parameters in microcutting, the present work is planned.

\section{Experimental Work}

The experiments were carried out on a three-axis multipurpose miniature machine tool, developed for high precision micromachining. The machine tool has dimensions of $560 \mathrm{~mm} \times 600 \mathrm{~mm} \times 660 \mathrm{~mm}$ and the maximum travel range in X-210 mm, in Y-110 mm and $110 \mathrm{~mm}$ in Z direction. Each axis has an optical linear scale with resolution of $0.1 \mu \mathrm{m}$, and closed loop feedback control ensures accuracy to submicron dimensions. The positioning resolution of machine is $0.1 \mu \mathrm{m}$ and the accuracy is $\pm 1 \mu \mathrm{m}$. Fig. 1 shows the experimental setup.

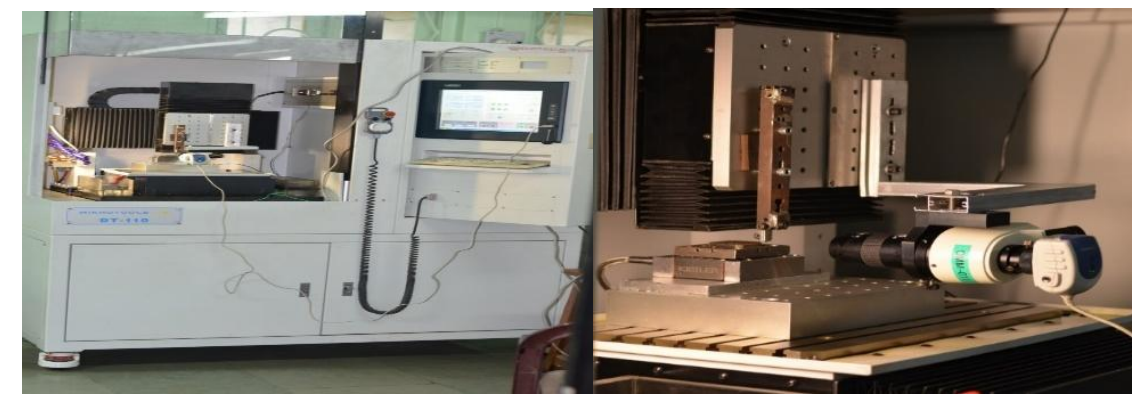

(a)

(b)

Fig. 1. (a) Machine Tool, and (b) machining set-up 
The effects of the cutting parameters on machining process responses of low carbon steel (AISI1215) and medium carbon steel (AISI1045) have been studied via a full factorial experimental design. The mechanism of cutting in terms of shear angle has been studied quantitatively whereas chip morphology qualitatively. A full factorial design yielded 48 runs (for each material AISI1215 and AISI1045, a total of 96 runs) and each run was replicated to characterize the experimental scatter in the data. Table 1 shows the factors and their levels selected.

Table 1 Factors and their levels

\begin{tabular}{|l|c|c|c|c|}
\hline Level & $\begin{array}{c}\text { Rake Angle } \\
(\mathrm{Deg})\end{array}$ & $\begin{array}{c}\text { Depth of Cut (DOC) } \\
(\mu \mathrm{m})\end{array}$ & $\begin{array}{c}\text { Cutting Speed }(\mathrm{V}) \\
(\mathrm{m} / \mathrm{min})\end{array}$ & Materials \\
\hline 0 & -5 & 25 & 1 & AISI1215 \\
\hline 1 & 0 & 50 & 2 & AISI1045 \\
\hline 2 & 5 & 75 & 3 & - \\
\hline 3 & 10 & 100 & - & - \\
\hline
\end{tabular}

The samples used for the experiments were heat treated at 3 different temperature i.e $950^{\circ}, 1050^{\circ}$ and $1200^{\circ}$ to study the effect of microstructure on the microcutting processes.

\section{Results and Discussion}

The mechanism of micro cutting is analyzed in terms of shear angle for AISI 1215 steel with the non-heat treated AISI 1215 steel and heat treated AISI 1215 steel at $950^{\circ} \mathrm{C}, 1050^{\circ} \mathrm{C}$ and $1200^{\circ} \mathrm{C}$. The chip thickness measurement is performed and the chip thickness ratio $\left(r_{c}\right)$ is determined using eq. (1).

$$
r c=\frac{t_{0}}{t_{c}}
$$

The governing equation for shear angle in a machining process is as given below:

$\operatorname{Tan} \varnothing=\frac{r_{c} \cos \propto_{n}}{1-r_{c} \sin \propto_{n}}$

Where,

$\mathrm{t}_{\mathrm{o}}=$ Uncut Chip Thickness

$\mathrm{t}_{\mathrm{c}}=$ Measured Chip Thickness

$\mathrm{r}_{\mathrm{c}}=$ Chip Thickness ratio

$\alpha_{n}=$ Rake angle

$\phi=$ Primary Shear Angle

During micro-cutting experiments, chips were collected using magnetic collector and used further for chip thickness measurement. Two chips of each experiment were inspected under the microscope; the images of the chips for various cutting parameters are shown in the fig. 2. 


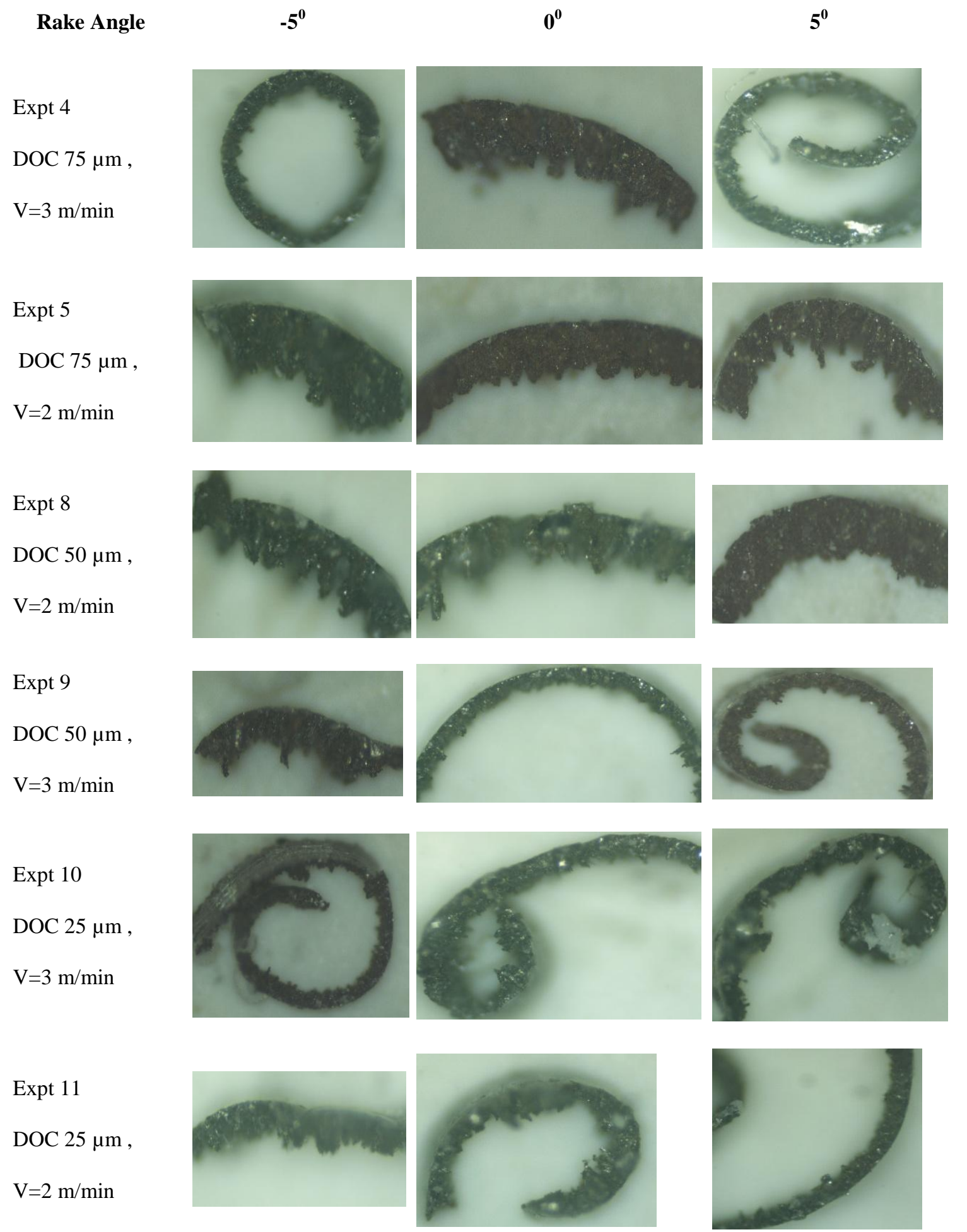

Fig. 2. Various forms of micro cutting chips

A variation of shear angle as a function of depths of cut varying from $25 \mu \mathrm{m}$ to $100 \mu \mathrm{m}$ for four different materials at a cutting speed of $3 \mathrm{~m} / \mathrm{min}$ is shown in fig. 3 (a-d). Similar plots have been prepared for the cutting speeds $2 \mathrm{~m} / \mathrm{min}$ see fig. 4 (a-d). 
Among the four materials chosen for this work, AISI 1215 heat treated steel at $1050^{\circ} \mathrm{C}$ shows the maximum shear angle at negative rake angle of $-5^{\circ}$ as the depth of cut changes from $25 \mu \mathrm{m}$ to $75 \mu \mathrm{m}$. On the other hand, AISI 1215 steel heat treated at $1200^{\circ} \mathrm{C}$ shows the lowest shear angle at all the depths of cut at $5^{\circ}$ or $10^{\circ}$ of rake angle as shown in fig. 3 (a-c).

At $25 \mu \mathrm{m}$ depth of cut, as the cutting speed decreases from $3 \mathrm{~m} / \mathrm{min}$ to $2 \mathrm{~m} / \mathrm{min}$, it is observed that the shear angle shows similar variation as the rake angle changes from $-5^{\circ}$ to $10^{\circ}$ which can be seen in fig. 3(a) and 4(a). AISI 1215 heat treated steel at $1050^{\circ} \mathrm{C}$, shows the highest shear angle at the cutting speeds of $3 \mathrm{~m} / \mathrm{min}$ whereas the lowest shear angle is evident in the case of AISI 1215 heat treated steel at $1200^{\circ} \mathrm{C}$, at higher cutting speed as shown in fig. 3. In general, at $25 \mu \mathrm{m}$ depth of cut, the shear angle is found to lie between $15^{\circ}$ to $20^{\circ}$.

At $25 \mu \mathrm{m}$ depth of cut, the shear angle varies for all materials between an average value of $19^{\circ}$ to $25^{\circ}$ for the rake angles of $0^{\circ}$ to $10^{\circ}$. The shear angle seems to be increasing at $-5^{\circ}$ negative rake angle, at $50 \mu \mathrm{m}$ depth of cut. As the cutting speed is decreased from $3 \mathrm{~m} / \mathrm{min}$ to $2 \mathrm{~m} / \mathrm{min}$ for $50 \mu \mathrm{m}$ depth of cut it is observed that the average shear angle varies between $15^{\circ}$ to $30^{\circ}$ for all four materials which is prevelant from fig. 3(b) and 4(b). AISI 1215 heat treated steel at $1200^{\circ} \mathrm{C}$ shows the lowest shear angle for all the rake angles from $0^{\circ}$ to $10^{\circ}$ at 50 $\mu \mathrm{m}$ depth of cut.

At $75 \mu \mathrm{m}$ depth of cut with cutting speed $3 \mathrm{~m} / \mathrm{min}$, the shear angle shows a large variations at $-5^{\circ}$ and $0^{\circ}$ rake angles. However, for $5^{\circ}$ and $10^{\circ}$ rake angles, the shear angle varies between $15^{\circ}$ to $25^{\circ}$ as observed in fig. $3(\mathrm{c})$. As the cutting speed decreases to $2 \mathrm{~m} / \mathrm{min}$, it is observed that at $75 \mu \mathrm{m}$ depth of cut, the shear angle shows an average value of $18^{\circ}$ to $30^{\circ}$ which can be witnessed from fig. 4(c).

At $100 \mu \mathrm{m}$ depth of cut the shear angle varies from $25^{\circ}$ to $40^{\circ}$ at negative rake angle of $-5^{\circ}$ and $0^{\circ}$ but average value of $20^{\circ}$ to $25^{\circ}$ of shear angle is seen at $5^{\circ}$ and $10^{\circ}$ rake angle. As the cutting speed decreases to $3 \mathrm{~m} / \mathrm{min}$ and $2 \mathrm{~m} / \mathrm{min}$, it is observed that at $100 \mu \mathrm{m}$ depth of cut, the shear angle shows a high variation as the rake angle changes from $-5^{\circ}$ to $10^{\circ}$ as observed in fig. 3(d) and $4(\mathrm{~d})$.

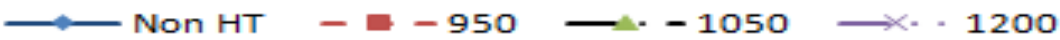

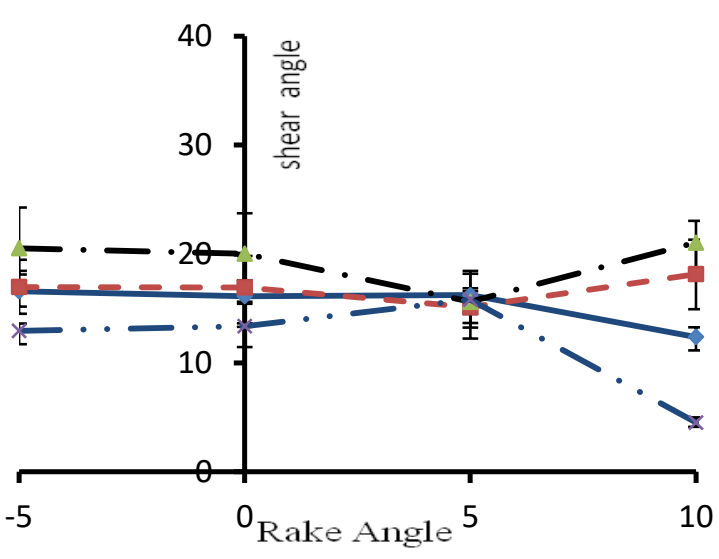

(a) depth of cut $25 \mu \mathrm{m}$

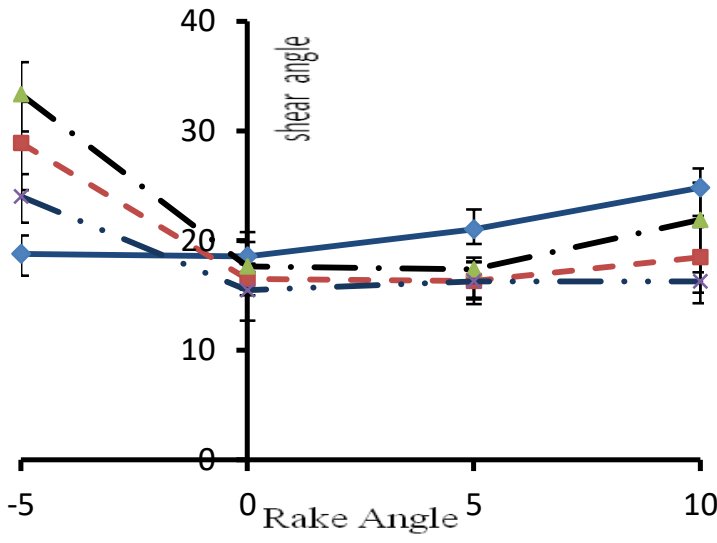

(b) depth of cut $50 \mu \mathrm{m}$ 


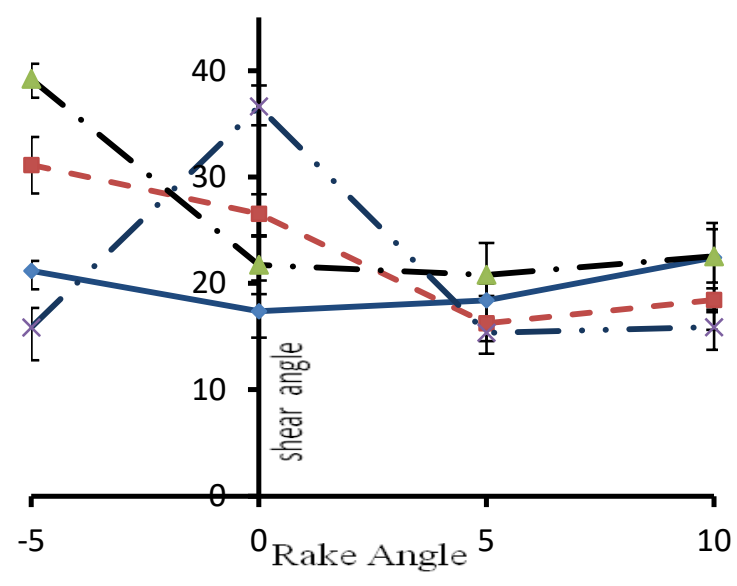

(c) depth of cut $75 \mu \mathrm{m}$

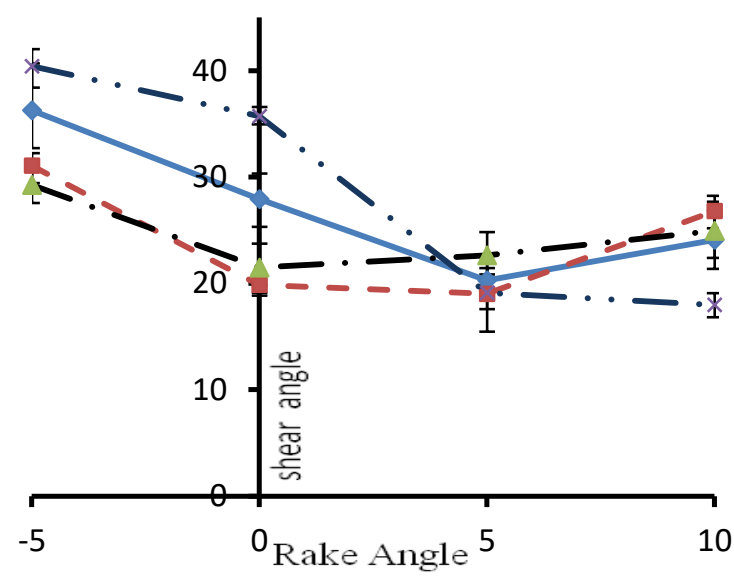

(d) depth of cut $100 \mu \mathrm{m}$

Fig. 3. Shear angle vs rake angle at $3 \mathrm{~m} / \mathrm{min}$ cutting speed

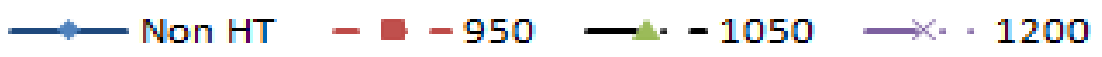

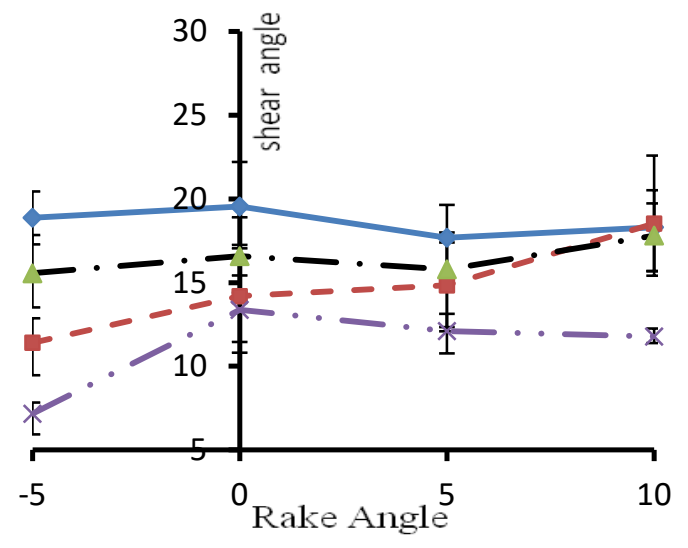

(a) depth of cut $25 \mu \mathrm{m}$

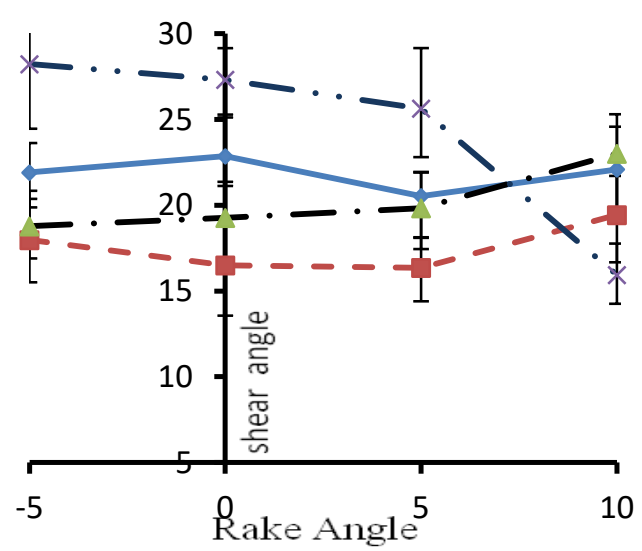

(c) depth of Cut $75 \mu \mathrm{m}$

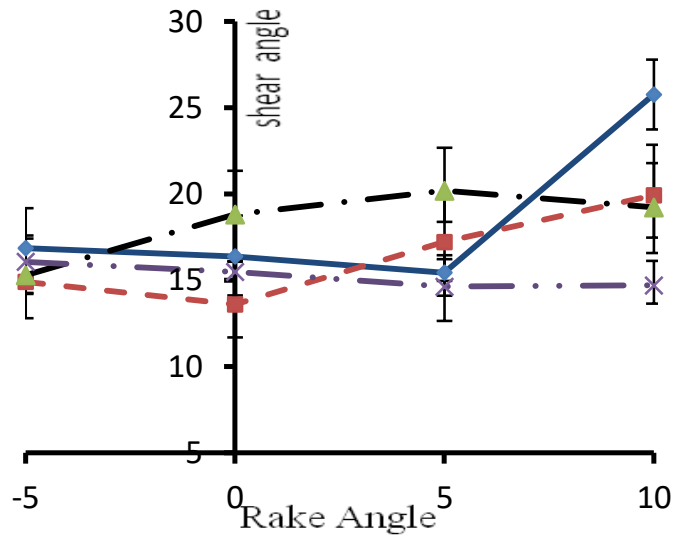

( b ) depth of cut $50 \mu \mathrm{m}$

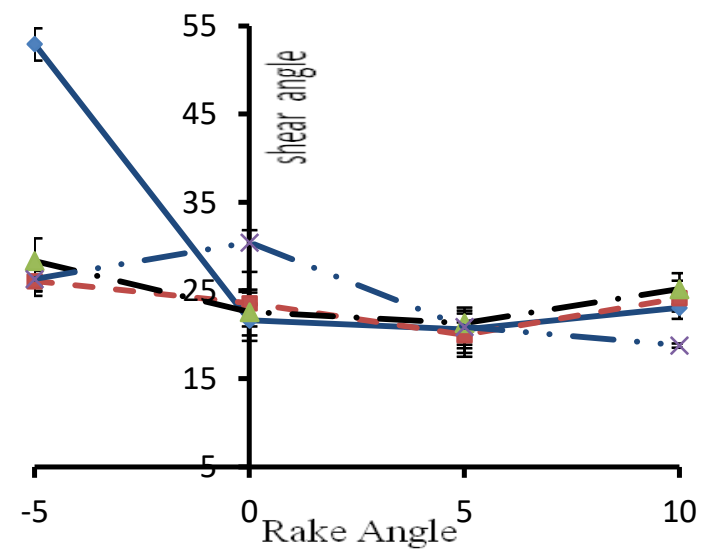

(d) depth of cut $100 \mu \mathrm{m}$

Fig. 4. Shear angle vs rake angle at $2 \mathrm{~m} / \mathrm{min}$ cutting speed 


\section{Conclusions}

Following conclusion can be drawn based on this work.

- At the rake angle of $10^{\circ}$, chips are by and large continuous. The chip segments appear to be joined together, though the line joining the segments borders can be easily observed.

- The chips do not show the formation of distinct saw tooth profile on the chip outer surface.

- The chips show minor serration along the chip outer surface. This indicates that, at $10^{\circ}$ rake angle, the chip thickness is by and large uniform for all four materials at lower cutting speed of $2 \mathrm{~m} / \mathrm{min}$.

- It is observed that the shear angle is larger at higher depths of cut of $75 \mu \mathrm{m}$ than at $25 \mu \mathrm{m}$. At $25 \mu \mathrm{m}$ depth of cut the shear angle varies from $7^{\circ}$ to $18^{\circ}$, whereas at $75 \mu \mathrm{m}$ depth of cut the shear angle varies between $15^{\circ}$ to $28^{\circ}$. This shows that machining could be difficult at lower depths of cut.

- At $3 \mathrm{~m} / \mathrm{min}$ by and large continuous chips are observed at both the rake angles of $-5^{\circ}$ and $10^{\circ}$.

- Analyses of chip morphology shows that, the shear angle is larger at higher depths of cut of $75 \mu \mathrm{m}$ than at $25 \mu \mathrm{m}$. At $25 \mu \mathrm{m}$ depth of cut, the shear angle varies from $7^{\circ}$ to $18^{\circ}$, whereas at $75 \mu \mathrm{m}$ depth of cut the shear angle varies between $15^{\circ}$ to $28^{\circ}$. This shows that machining could be difficult at lower depths of cut.

- Analyses of chip segment per unit length show that, the number of segments reduces as the rake angle increases for all the four work materials that were heat treated at the various temperatures.

- AISI 1215 non heat treated steel has good machinablity at negative rake angle whereas AISI 1215 steel heat treated at $1200^{\circ} \mathrm{C}$, shows the lowest shear angle at all the depths of cut at $5^{\circ}$ or $10^{\circ}$ of rake angle, for all cutting speeds. This indicates that, this material has relatively lower machinability.

\section{References}

[1]. Masuzawa, T.; Tönshoff, H.K. Three-dimensional micromachining by machine tools. CIRP AnnalsManufacturing Technology 1997, 46, 621-628. [2] D. Dornfeld, S. Min, Y. Takeuchi, "Recent advances in Mechanical Micromachining”, Annals of CIRP, Vol. 55, pp. 745-768, 2006.

[2]. X. Liu, R.E. Devor, S.G. Kapoor, "The mechanics of machining at the microscale: Assessment of the current state of the science", J. Manuf. Sci. \& Tech., Trans. ASME, Vol. 126, pp. 666-678, 2006.

[3]. J. Mats, "Ultraprecision diamond turning of aluminium single crystals", Proc. Tech Vol. 63 (1-3), pp. 157-162, 1997.

[4]. Moriwaki T., Sugimura N., Manabe K., and Iwata K., "A Study on Orthogonal Micromachining of Single Crystal Copper”,Transaction of the NAMRI/SME, Vol. 19, pp. 177-183, 1991.

[5]. Liu Zhanqiang \& Shi Zhenyu \& Wan Yi, "Definition and determination of the minimum uncut chip thickness of microcutting" Int J Adv Manuf Technol, Vol. 69, PP 1219-1232, 2013.

[6]. Vogler, M. P., DeVor, R. E., and Kapoor, S. G., "On the Modeling and Analysis of Machining Performance in Micro-endmilling, Part I: Surface Generation,'” ASME J. Manuf. Sci. Eng, pp. 684693, 2004.

[7]. Ship-Peng Lo,"An analysis of cutting under different rake angles using the finite element method", Journal of Materials Processing Technology,105, pp. 143-151, 2000.

[8]. R. S. Pawade and Suhas S. Joshi, "Mechanism of chip formation in high-speed turning of Inconel 718", Machining Science and Technology: An International Journal,15:1, pp. 132-152, 2011.

[9]. H. Ernst, Physics of Metal Cutting, Machining of Metals, ASM, Cleveland, 1938, pp. 1-34.

[10]. M.E. Merchant, Basis mechanics of the metal-cutting process, ASME J. Appl. Mech. 11 (1944) A168A175.

[11]. W.B.Leehe,M.Zhou, "A Theoretical analysis of effect of crystallographic orientation on chip formation in micromachining”, Int.J.Mach.Tools Manufact, Vol. 33, No-3, pp. 439-447, 1993.

[12]. Raju S. Pawade,D.S.N. Reddy, Ganesh S. Kadam, "Chip segmentation behaviour and surface topography in high-speed turning of titanium alloy (Ti-6Al-4V) with eco-friendly water vapour", Int. J. Machining and Machinability of Materials, Vol. 13, Nos. 2/3, pp. 113-135, 2013.

[13]. A. Simoneau, E. Ng, M.A. Elbestawi, "Chip formation during microscale cutting of a medium carbon steel”, International Journal of Machine Tools \& Manufacture , Vol. 46, pp. 467-481, 2006. 